\title{
Peritoneal pseudomyxoma associated with synchronic malignant mucinous neoplasias of the cecum, appendix and rectum. Case report and review of the literature ${ }^{1}$
}

\author{
Pseudomixoma peritoneal associado a neoplasias malignas mucinosas do ceco, \\ apêndice e reto. Relato de caso e revisão da literatura
}

\author{
Rogério Saad-Hossne², René Gamberini Prado², Alexandre Bakonyi Neto², Maria Aparecida Marchezan ${ }^{3}$ \\ 1. Study performed at the Experimental Surgery Laboratory, Department of Surgery and Orthopedics, School of Medicine, State University of São \\ Paulo (UNESP), Botucatu - SP Brazil. \\ 2. PhD, Assistant Professor, Department of Surgery and Orthopedics, School of Medicine, UNESP, Botucatu - SP, Brazil. \\ 3. Ph.D, Full Professor, Department of Pathology, School of Medicine, UNESP, Botucatu - SP, Brazil.
}

\begin{abstract}
Peritoneal pseudomyxoma is a pathological condition that compromises the peritoneum, characterized by the production of large quantities of mucinous liquid, which progressively fills the peritoneal cavity, originating in general from mucinous appendicular or ovarian tumors. We report a peritonial pseudomyxoma associated with mucinous adenocarcinoma of the appendix synchronic with adenocarcinoma of the rectum in 44 years old patient, where the initial diagnosis was rectal adenocarcinoma. Tumour of the appendix and peritonial pseudomyxoma were incidental and found intraoperativelly. We focus the histological patterns of the lesions, diagnosis and the treatment, with revision of the literature. Key words: Pseudomyxoma Peritonei. Adenocarcinoma. Adenocarcinoma, Mucinous. Appendix. Rectum.

\section{RESUMO}

O pseudomixoma peritoneal é uma condição patológica que acomete o peritoneo, caracterizada pela produção de grandes quantidades delíquido mucinoso, queprogressivamente preenche a cavidade peritoneal, tendo em geral como origem tumores mucinosos apendiculares ou de ovário. Relatamos a ocorrência de um pseudomixoma peritoneal associadoa adenocarcinoma mucinosodoapêndicesincrônicoeadenocarcinomadoretoempacientede44anos, cujodiagnósticoinicialfoideadenocarcinoma do reto. A neoplasia do apêndice e o pseudomixoma peritonial foram achados incidentais, intra-operatórios. Enfocamos as principais características anatomo-patológicas das lesões, o diagnóstico e tratamento, através de ampla revisão da literatura. Descritores: Pseudomixoma Peritoneal. Adenocarcinoma. Adenocarcinoma mucinoso. Apêndice. Reto.
\end{abstract}




\section{Introduction}

Peritoneal pseudomyxoma is a pathological condition that compromises the peritoneum, characterized by production of large quantities of mucinous liquid with gelatinous aspect, that progressively fills the peritoneal cavity1. The primary lesion has been originated, in general, from adenoma or mucinous appendicular adenocarcinoma or ovarian tumors. The dissemination occurs by rupture of the lesion with release of neoplastic cells of mucus into abdominal cavity in a process known as disseminated peritoneal adenomucinosis. The production of a large quantity of mucinous with translucent aspect, carries a progressive accumulation in the abdominal and pelvic cavity, and able to produce partial or complete obstructive symptoms $^{1-3}$. It presents low incidence and reserved prognosis. The mean survival time is 6 year; however the survival rate at 5 and 10 years is $50-70 \%$ and $10-32 \%$, respectively. The prognosis varies with the nature of the tumor, and relapses are frequent ${ }^{4}$. In general, the clinical syntms are similar to that of acute appendicitis4,2,5. Treatment is also the object of discussions, with diverse techniques, procedures and drugs still being studied. It consists of surgical removal of the primary site, followed by ressection of the parietal peritoneum and intraperitoneal chemotherapy according to the Sugarbaker technique. Most of difficulties have arisen to definition of peritonial pseudomyxoma, since this term is applied to a heterogeneous groups of lesions associated with a unique morphological expression. Herein we describe a case of peritonial pseudomyxoma associated with synchronic malignant neoplasias of the cecal appendix and rectum.

\section{Case report}

A male patient aged 44 years old, with complainsof tenesmus and hematochezia for 2 months, was diagnosed by digital rectal exam having a hard exotitic lesion in the anterior wall of the rectum, painfully, with little mobility,

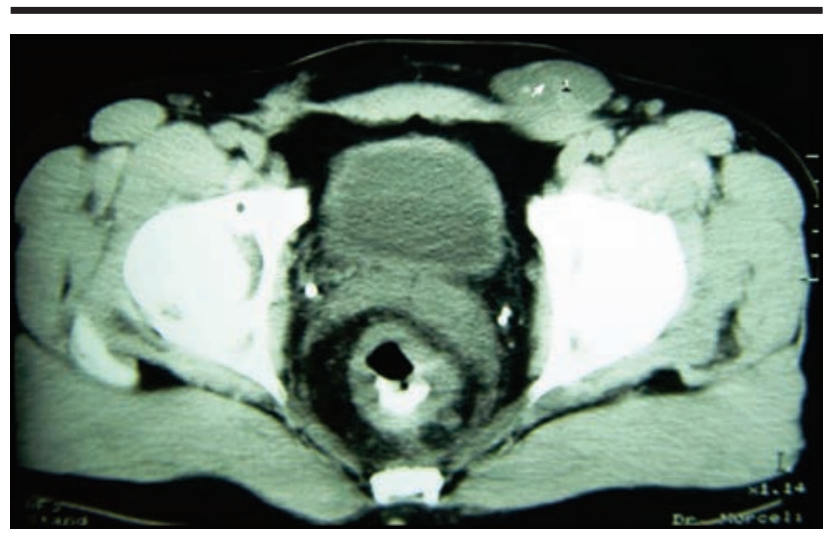

FIGURE 1 - CT-scan evidenced a partially obstructive lesion in the rectum disted $5 \mathrm{~cm}$ from the anal border. The colonoscopy showed a lesion suggestive of rectal neoplasia, occupying $60 \%$ of the rectal lumen, disted $4 \mathrm{~cm}$ from the line pectin. The biopsy demonstrated mucinous adenocarcinoma of the rectum, and CT-stan evidenced a partially obstructive lesion in the rectum (figure 1), with partial invasion of the rectal wall and without lymphomegalies, invasion of adjacent structures or distant lesions. Blood tests and the levels of carcinoembrionary antigen (CEA) were normal. The patient were submitted to neoadjuvant radiotherapy (4500cGY) and chemotherapy with 5FU and leucovorin, according to our protocol. He was reevaluated after 6 weeks and a new CT/scan showed reduction of the lesion size. Endoscopic evaluation showed reduction in tumor size, presenting as a flat lesion, slightly exotitic, with areas of necrosis, occupying 30\% of the lumen (partial response). Biopsy demonstrated residual adenocarcinoma. With these findings, abdomino-perineal amputation of the rectum was proposed. Laparotomy revealed a large quantity of mucus in the peritoneal cavity $(500 \mathrm{ml})$, absence of hepatic lesions, without signs of invasion in the pelvic cavity. There was a lesion with mucoid pattern in contact with the cecal appendix, which was turgid and of hard consistency (figure 2). A frozen biopsy demonstrated mucinous adenocarcinoma of the appendix. The presence of a synchronic tumor resulted in a rectal amputation with right colectomy and lymphatic nodes resection, followed by ileo-transverse anastomosis and terminal colostomy in the left side. The diagnose was a mucinous adenocarcinoma of the appendix, presented as a rupture mucocele, with dissemination into the peritonial cavity. Initial syntoms were related to the rectal lesion, classified as a pT3 M2 mucinous adenocarcinoma, synchronic with the cecal apendice lesion. The immunohistochemical study showed positive expression for Ck-20 and negative for Ck-7 in neoplasic cells of the mucinosos implants in the peritoneum and in lesions of the cecal appendix and rectum. The patient was submitted to adjuvant treatment by the technique described by Sugarbaker7.

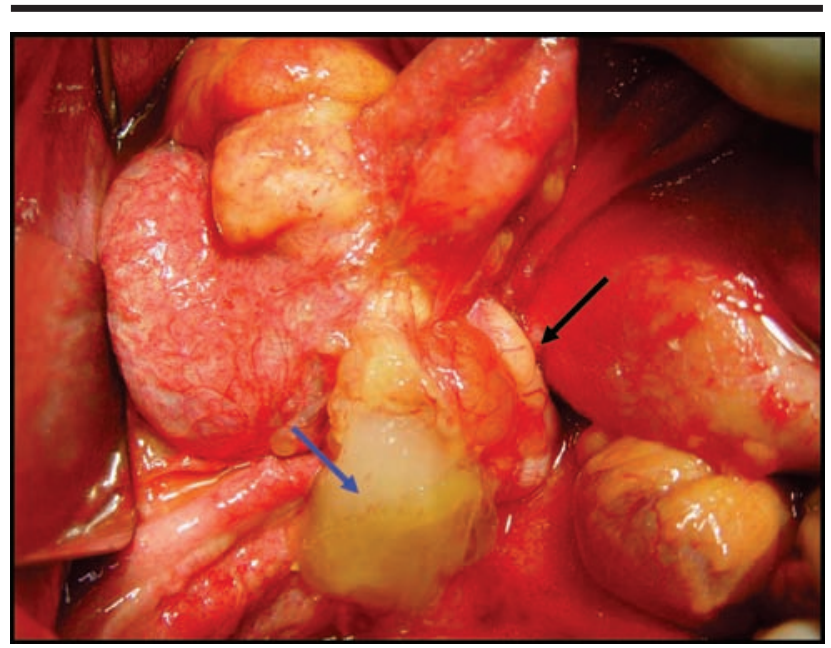

FIGURE 2 - Mucoid pattern (blue arrow) in contact with the cecal appendix (black arrow) 


\section{Discussion}

The term peritoneal pseudomyxoma was used originally to describe mucinous ascites associated with appendicular mucocele rupture and lattelly used to all conditions associated with accumulations of mucus in the abdominal cavity4,6,2. In this manner the term pseudomyxoma is applied to clinical and radiological aspects, without histopathological characterization, and may be considered syndromic,5,3. Despite the advances occurred in the past decade in the comprehension of mucinous neoplasias of the appendix and its relation to peritoneal pseudomyxoma, remains among pathologists and surgeons difficulties in the classification of these lesions, since the first descriptions of Gibbs 830 years ago. Appendicular mucoceles are uncommon entities generally associated with various pathological conditions. Pai and Longacre3 inorder to clarify the characteristics seven of these lesions and to supply directions for diagnosis and prognosis of its biological behavior, evaluated the clinicopathological characteristics of mucinous neoplasias of the appendix with or without association with pseudomyxoma peritonial, at the University of Stanford during the last 40 years3. They classified the lesions as:

\section{1) Simple mucoceles}

2) Mucosal hyperplasia and hyperplastic polyps

3) Serrulate adenoma (mixture of hyperplastic and adenomatous polyp)

Diagnosis of serrulate adenoma implicit in one benign lesion without risk of relapse after complete resection, and reported without association with peritoneal pseudomyxoma9,10 .

\section{4) Mucinous cystadenoma}

Mucinous cystadenoma is described as a lesion analogous to colonic adenomas, but which some characteristics that differentiate it from this, such as growth, origin, genetic and immunophenotypic patterns11,12.

5)Mucinousneoplasiaofuncertainmalignantpotential

According to the authors3, this classification must only be used for extremely well-differentiated mucinous neoplasias that extend through the appendicular wall, without a clear association with wall invasion and infiltration. The cecal appendices wall can be compromised by distortion, distention of the lumen, caused by excess of mucus production.

\section{6) Mucinous neoplasia of low potential malignancy}

This neplasia is responsible for the majority of peritoneal pseudomyxoma cases. Macroscopically it is indistinguishable from mucinous adenomas, being able to present signs and symptoms of a dilated appendix and adherence to neighboring structures11,13. The clinical presentation of this neoplasia is similar to that of mucinous adenoma. Preoperative diagnosis is rare, and even the intraoperative diagnosis is made in less than $1 / 3$ of cases.

\section{7) Invasive adenocarcinoma}

Invasive adenocarcinoma (mucinous, intestinal or signet ring) of the appendix is rare and less frequent than mucinous adenomas. Histologically it is classified as mucinous, intestinal or in signet ring14. Mucinous adenocarcinomas represent approximately $40 \%$ of all adenocarcinomas, are uncommon, with little association with pseudomyxoma characterized by low quantity of mucin (less than 50\%) and by being invasive and presenting a high degree of cellular atypias15. We can conclude that although there have been attempts to elaborate a classification of mucinous tumors of the appendix, it remains controversial as a consequence of a variety of diagnostic terms applied to these neoplasias. In the present case the primary lesion was a mucionous adenocarcinoma of the appendix, macroscopically expressed as a mucocele rupture, with dissemination into peritonial cavity. The appropriate treatment for these tumors is right hemicolectomy and lynehadenectomy drainage, mainly when the lesion is restricted to the appendix, which can increase the cure16,17. Although the tumor is disseminated throughout the peritoneal cavity 6 with frequent compromise of the ovary, the invasion of visceral organs is very rare, without occurrence of metastasis, lymphatic or hematological spred. Extraperitoneal dissemination of the disease, such as pleural extension, is uncommon, and is in general secondary to aggressive cytoreductive therapy or rarely due to the presence of pleuroperitoneal congenital communication 18. Hhistological patterns of mucinous implants consist of amorphous mucinous material, with non-invasive fibrotic tissue presenting secretory epithelium of mucin. The neoplastic cells in general are CK20-positive and CK7-negative, although the expression of CK7 would be observed in up to $30 \%$ of the cases. The use of these markers is not useful in determining the origin of the lesions2. In the majority of cases the patterns of immunoreactivity are identical in mucinous neoplasias of the appendix and of the ovary3. Another relevant prognostic factor is the degree of cellularity and cytological atypias. Lesions with a large quantity of cellular atypias and epithelial hyperproliferation have a worse prognosis with greater chance of implantation in the peritoneal cavity3. The morbidity and mortality are significantly worse in cases of peritoneal carcinomatosis with mucinous ascite secondary to mucinous carcinomas than in those cases of mucinous neoplasias of low-degree malignancy19,3. In this connection, it is important to determine the histological characteristics of the primary lesion, since in these patients whose initial focus is a lowdegree mucinous adenocarcinoma, the benefits of extensive peritonectomy are questionable4,20,21. Differential diagnoses of pseudomyxoma include mucinous colloid adenocarcinoma with mucinous ascite (peritoneal 
carcinomatosis), endometriosis and drainage of mucin secondary to non-neoplastic inflammatory processes $2,22-$ 24. The standard treatment consists of a surgical approach toward an appendectomy or right hemicolectomy. New surgery can be repeated to reduce the tumor mass and mucus production23-26. This treatment is not curative, but it is useful to limit the production and accumulation of mucus and its obstructive effects. Relapse is frequent and requires new surgical interventions, which each time become more difficult and laborious due to fibrous adherences 25 . One more aggressive option is the association of a radical surgical approach together with systemic and intraperitoneal chemotherapy. This procedure has been adopted by some authors with good survival rate and even cure25-30 In the present case, having in view synchronism between the neoplasias of the rectum and of the appendix, our option was right hemicolectomy with lymphadenectomyresection and amputation of the rectum. The treatment of pseudomyxoma remains controversial, with ample variety of surgical and chemotherapy procedures proposed, which necessitate new studies26-28,31,32. The procedure described by Sugarbaker5,32,33 was developed from these bases and consists of six procedures of peritonectomy, with the objective of removing the peritoneal surfaces with the lesions and include omentectomy-splenectomy, left and right peritonectomy, and that of the hemidiaphragm, cholecystectomy, antrectomy and removal of the pelvic peritoneum, jointly with the association of intraperitoneal chemotherapy with mitomycin C associated with hypetermia $\left(40-44^{\circ} \mathrm{C}\right) 28,32$. The chemotherapies are instilled in the peritoneal cavity with the objective that all the intra-abdominal surfaces makes contact with the drugs, being realized during the operative procedure and involving continuous manipulation of the visceras by the surgeon for a period of 90 minutes, increasing the contact with peritoneal surfaces. Systemic chemotherapy is realized in the first days after surgery27,28. The mean survival rate after 5 years is $70 \%$ for the patients treated with cytoreduction and intraperitoneal chemotherapy with mitomycin C, associated with hypetermia29. Two other studies, one utilizing a cytoreduction scheme, intraperitoneal chemotherapy (mitomycin $\mathrm{C}$ and 5-fluorouracil (5-fu)), followed by three cycles of mitomycin $\mathrm{C}$ and $5 \mathrm{fu}$, and the other by utilizing cytoreductive surgery, systemic intraperitoneal chemotherapy with mitomycin $\mathrm{C}$ showed survival rates of $75 \%$ in 5 years6. A third study 27 showed survival rates of $86 \%$ and $68 \%$ after 5 and 10 years respectively, utilizing the scheme of cytoreduction, intraperitoneal chemotherapy and hypetermia with mitomycin $\mathrm{C}$ and 5-fu, followed by three cycles of mitomycin and 5 fu intravenous7. The postoperative complications most frequently observed are anastomotic fistulas, formation of cutaneous fistulas, wound infection, obstruction and perforation of the small intestine and pancreatitis. A North American cost estimation for treatment utilizing the Sugarbaker scheme, calculates US\$ 166,922 as the total cost of this treatment26. In a recent systematic review4, there was a proof of the efficacy of the procedure proposed by Sugarbaker for the treatment of peritoneal pseudomyxoma. However, data from the literature are limited, with few controlled and randomized studies having the view that peritonial pseudomyxoma is a rare disease and most of these studies focused a small series of cases. A recent review by Bryant and col.33 (2005), included only groups of patients with similar histological aspect and prognosis, applying the definition of peritoneal pseudomyxoma to cases of disseminated peritoneal adenomucinosis and excluding peritoneal carcinomatosis and its hybrids variant.

\section{References}

1. Sugarbaker PH, Ronnett BM, Archer A, Averbach AM, Bland R, Chang D. Pseudomyxoma peritonei syndrome. Adv Surg. 1996;30:233-80.

2. Ronnett BM, Yan H, Kurman RJ. Patients with pseudomyxoma peritonei associated with disseminated peritoneal adenomucinosis have a significantly more favorable prognosis than patients with peritoneal mucinous carcinomatosis. Cancer. 2001;92:85-91.

3. Pai R, LongacreT A. Appendiceal mucinous tumors and Pseudomyxoma Peritonei: histologic features, diagnostic problems, and proposed classification. Adv Anat Pathol. 2005;12:291-311.

4. Hinson FL, Ambrose NS. Pseudomyxoma peritonei. $\mathrm{Br}$ J Surg. 1998; 85:1332-9.

5. Bryant J, Clegg AJ, Sidhu MK, Brodin H, Royle P, Davidson P. Systematic review of the Sugarbaker procedure for pseudomyxoma peritonei. Br J Surg. 2005;92:153-8.

6. Sugarbaker PH. Pseudomyxoma peritonei. A cancer whose biology is characterized by a redistribution phenomenon. Ann Surg. 1994;219:109-11.

7. Sugarbaker PH, Zhu BW, Sese GB, Shmookler B. Peritoneal carcinomatosis from appendiceal cancer: results in 69 patients treated by cytoreductive surgery and intraperitoneal chemotherapy. Dis Colon Rectum. 1993;36:323-9.

8. Gibbs NM. Mucinous cystadenoma and cystadenocarcinoma of vermiform appendix with particular reference to mucocele and pseudomixoma peritonei. J Clin Pathol. 1973;26:413-21.

9. Jass JR, Whitehall VL, Young J. Emerging concepts in colorectal neoplasia. Gastroenterology. 2002;123:862-76.

10. Iino H, Jass JR, Simms LA, Zhu BW. DNA microsatellite instability in hyperplastic polyps, serrated adenomas, and mixed polyps: a mild mutator pathway for colorectal cancer? J Clin Pathol. 1999;52:5-9.

11. Shih IM, Yan H, Speyrer D, Zhu BW. Molecular genetic analysis of appendiceal mucinous adenomas in identical twins, including one with pseudomyxoma peritonei. Am J Surg Pathol. 2001;25:1095-9.

12. Kabbani W, Houlihan PS, Luthra R. Mucinous and 
nonmucinous appendiceal adenocarcinomas: different clinicopathological features but similar genetic alterations. Mod Pathol. 2002;15:599-605.

13. Misdraji J, Yantiss RK, Graeme-Cook FM, Kurman RJ. Appendiceal mucinous neoplasms: a clinicopathologic analysis of 107 cases. Am J Surg Pathol. 2003;27: 1089-103.

14. Ronnett BM, Kurman RJ, Shmookler BM. The morphologic spectrum of ovarian metastases of appendiceal adenocarcinomas: a clinicopathologic and immunohistochemical analysis of tumors often misinterpreted as primary ovarian tumors or metastatic tumors from other gastrointestinal sites. Am J Surg Pathol. 1997;21:1144-55.

15. McCusker ME, Cote TR, Clegg LX, Shmookler BM. Primary malignant neoplasms of the appendix: a population-based study from the surveillance, epidemiology and end-results program, 1973-1998. Cancer. 2002;94:3307-12.

16. Cortina R, McCormick J, Kolm P. Management and prognosis of adenocarcinoma of the appendix. Dis Colon Rectum. 1995;38:848-52.

17. Varisco B, McAlvin B, Dias J, Shmookler BM. Adenocarcinoid of the appendix: is right hemicolectomy necessary? A meta-analysis of retrospective chart reviews. Am Surg. 2004;70:593-99.

18. Pestieau SR, Esquivel J, Sugarbaker PH. Pleural extension of mucinous tumor in patients with pseudomyxoma peritonei syndrome. Ann Surg Oncol. 2000;7:199-203.

19. Yan H, Pestieau SR, Shmookler BM,. Histopathologic analysis in 46 patients with pseudomyxoma peritonei syndrome: failure versus success with a second-look operation. Mod Pathol. 2001;14:164-71.

20. Gonzalez-Moreno S, Sugarbaker PH, Clegg AJ. Right hemicolectomy does not confer a survival advantage in patients with mucinous carcinoma of the appendix and peritoneal seeding. Br J Surg. 2004;91:304-11.

21. Bryant J, Clegg AJ, Sidhu MK, Sugarbaker PH. Systematic review of the Sugarbaker procedure for pseudomyxoma peritonei. Br J Surg. 2005;92:153-8.

22. Zissin R, Gayer G, Kots E. Imaging of mucocoele of the appendix with emphasis on the CT findings: a report of 10 cases. Clin Radiol. 1999;54:826-32.

23. Kurita M, Komatsu H, Hata Y, Iino H. Pseudomyxoma peritonei due to adenocarcinoma of the lung: case report. J Gastroenterol. 1994;29:344-8.

24. Hameed A, Jafri N, Copeland LJ, Iino H. Endometriosis with myxoid change simulating mucinous adenocarcinoma and pseudomyxoma peritonei. Gynecol Oncol. 1996;62:317-9.

25. Esquivel J, Sugarbaker PH. Pseudomyxoma peritonei in a hernia sac: analysis of 20 patients in whom mucoid fluid was found during a hernia repair. Eur J Surg Oncol. 2001;27:54-8.

26. NHS - Centre for Reviews and Dissemination. Undertaking systematic reviews of research on effectiveness: CRD's guidance for those carrying out or commissioning reviews. 2nd ed. CRD Report 4. York: NHS Centre for Reviews and Dissemination; 2001.

27. Van Ruth S, Acherman YIZ, van de Vijver MJ, Hart AAM, Verwaal VJ, Zoetmulder FAN. Pseudomyxoma peritonei: a review of 62 cases. Eur J Surg Oncol. 2003;29:682-8.

28. Lilford R, Braunholtz D, Harris J, Gill T. Trials in surgery. Br J Surg. 2004;91:6-16.

29. Smith JW, Kemeny N, Caldwell C, Banner P, Sigurdson E, Huvos A. Pseudomyxoma peritonei of appendiceal origin. The Memorial Sloan-Kettering Cancer Center experience. Cancer. 1992;70:396-401.

30. Cancer Service Website [homepage on the internet]. Dublin; 2004 [cited 2004 apr 20]. Available from: http://www.advisorybodiesdoh.gov.uk/nscag.

31. Briggs AH. Handling uncertainty in cost-effectiveness models. Pharmacoeconomics. 2000;17:479-500.

32. Sugarbaker PH. Cytoreductive surgery and perioperative intraperitoneal chemotherapy as a curative approach to pseudomyxoma peritonei syndrome. Eur J Surg Oncol. 2001;27:239-43.

33. Bryant J, Clegg A J, Sidhu M K, Brodin H, Royle P, Davidson P. Systematic review of the Sugarbaker procedure for pseudomyxoma peritonei. Br J Surg. 2005;92:153-8.

\section{Correspondence:}

Rogério Saad Hossne

Faculdade Medicina Botucatu - UNESP

Distrito de Rubião Júnior, s/n

18618-000 Botucatu - São Paulo Brazil

Phone: (55 14)3811-6269

Fax: (55 14)3882-5475

saad@fmb.unesp.br
Conflict of interest: none Financial source: none

Received: March 12, 2007

Review: May 14, 2007

Accepted: June 11, 2007

\section{How to cite this article}

Saad-Hossne R, Prado RG, Bakonyi Neto A, Marchezan MA. Peritoneal pseudomyxoma associated with synchronic malignant mucinous neoplasias of the cecum, appendix and rectum: case report and review of the literature. Acta Cir Bras. [serial on the Internet] 2007 Sept-Oct;22(5). Available from URL: $\underline{\text { http://www.scielo.br/acb }}$ 